\title{
Modeling of the circulation in the Northwestern Mediterranean Sea with the Princeton Ocean Model
}

\author{
M. A. Ahumada ${ }^{1}$ and A. Cruzado $^{2}$ \\ ${ }^{1}$ Instituto de Recursos, Universidad del Mar, Puerto Angel, Oaxaca, México \\ ${ }^{2}$ Centre d'Estudis Avançats de Blanes, CSIC, Blanes, Catalonia, Spain
}

Received: 4 April 2006 - Published in Ocean Sci. Discuss.: 9 August 2006

Revised: 14 November 2006 - Accepted: 2 February 2007 - Published: 9 February 2007

\begin{abstract}
The Princeton Ocean Model - POM (Blumberg and Mellor, 1987) has been implemented in the Northwestern Mediterranean nested (in one-way off-line mode) to a general circulation model of the Mediterranean Sea - OGCM (Pinardi and Masetti, 2000; Demirov and Pinardi, 2002) in order to investigate if this model configuration is capable of reproducing the major features of the circulation as known from observations and to improve what has been made by previous numerical modeling works. According to the model results, the large-scale cyclonic circulation in the northern part of the Northwestern Mediterranean is, at least in the upper layers, less coherent in winter and spring than in summer and autumn. Furthermore, there is evidence that the mesoscale structure (eddies and meanders) is, during all year, a significant dynamic characteristic in this region of the Mediterranean Sea. Finally, concerning the circulation in the lower layers, the model results have confirmed that Levantine Intermediate Water (LIW) and Western Mediterranean Deep Water (WMDW) follow essentially a cyclonic path during all year.
\end{abstract}

\section{Introduction}

The Mediterranean Sea is a semi-enclosed sea acting like an ocean system in which several temporal and spatial scales (basin, subbasin, and mesoscale) interact to form a highly complex and variable circulation (Fernández et al., 2005). Millot (1991) has mentioned that the major surface currents flowing along slope, can be affected by instability processes that sometimes lead to the generation of turbulent phenomena such as mesoscale eddies, which can induce relatively intense currents and great heterogeneity of the hydrological characteristics. On the other hand, Send et al. (1999) sustain

Correspondence to: A. Cruzado

(cruzado@ceab.csic.es) that the development of an upper mixed layer by summer solar heating and the convective processes caused by winter cooling and strong winds produce seasonal changes in the near-surface circulation whose effects mainly consist of modulations in the intensity and smaller scale variability of the current systems. More recently, Molcard et al. (2002) have suggested that the main permanent features of the general circulation (Gulf of Lions cyclonic gyre, Rhodes cyclonic gyre, Gulf of Syrte anticyclonic gyre) are induced by the permanent wind stress curl structure. They point out that the magnitude and spatial variability of the wind is important in determining the appearance or disappearance of some gyres such as the Tyrrhenian anticyclonic gyre and the Ionian cyclonic gyre. Concerning the circulation at deeper layers, it is generally accepted that it follows the topography of the different subbasins (La Violette, 1990), describing basically a cyclonic path.

In the last years, the Mediterranean Sea has been subject to several numerical modeling works focused mainly on the study of the circulation and mechanisms that generate it at different temporal and spatial scales (Menzin and Moskalenko, 1982; Heburn, 1987; Malanotte-Rizzoli and Bergamasco, 1989, 1991; Stanev et al., 1989; Beckers, 1991; Tziperman and Malanotte-Rizzoli, 1991; Bergamasco et al., 1993; Pinardi and Navarra, 1993; Alvarez et al., 1994; Haines and Wu, 1995; Roussenov et al., 1995; Zavatarelli and Mellor, 1995; Herbaut et al., 1996; Wu and Haines, 1996; Herbaut et al., 1997; Brankart and Brasseur, 1998; Castellari et al., 1998; Drakopoulos and Lascaratos, 1999; Bergamasco et al., 1999; Pinardi and Masetti, 2000; Beckers et al., 2002; Demirov and Pinardi, 2002; Molcard et al., 2002; Zavatarelli et al., 2002; Brenner, 2003; Echevin et al., 2003; Korres and Lascaratos, 2003; Sorgente et al., 2003; Tonani, 2003; Zavatarelli and Pinardi, 2003; Fernández et al., 2005; Jordà, 2005; and others). Nevertheless, the variety of models, configurations, parameterizations, resolutions, forcing, etc., found in the literature on numerical modeling of

Published by Copernicus GmbH on behalf of the European Geosciences Union. 


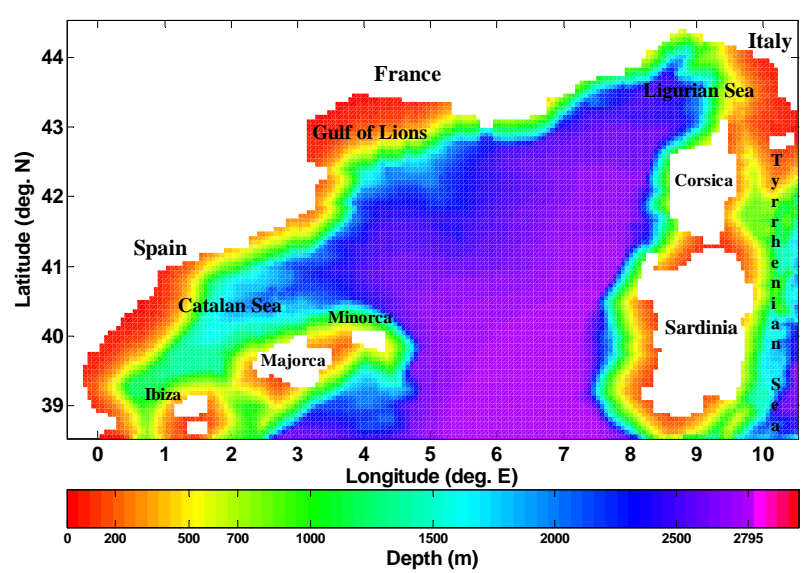

Fig. 1. The Northwestern Mediterranean Sea Model Domain and Bottom Topography based on the U.S. Navy Digital Bathymetric Data Base 5.

the Mediterranean Sea circulation, in some way, suggest that no single model is going to be the best one for all applications. In this context, the state of the art continuously offers new perspectives with room for improvements of model design, formulations, parameterizations, etc. In this work, a numerical modeling system based on the Princeton Ocean Model (Blumberg and Mellor, 1987) has been implemented in the Northwestern Mediterranean nested (in one-way offline mode) to a general circulation model of the Mediterranean Sea - OGCM (Pinardi and Masetti, 2000; Demirov and Pinardi, 2002) in order to investigate if this model configuration is capable of reproducing the major features of the circulation as known from observations and to improve what has been made by previous numerical modeling works.

This article is organized as follows. A brief description of the principal characteristics of the Princeton Ocean Model, along with details of its configuration for the Northwestern Mediterranean Sea is given in Sect. 2. Atmospheric forcing and initial conditions used for the climatological integration of this model configuration are briefly analyzed in Sect. 3. The model results and discussions are presented in Sect. 4, and conclusions are offered in Sect. 5.

\section{Numerical model}

\subsection{Model description}

The Princeton Ocean Model (POM) is a 3-D primitive equations ocean circulation model, which has been described in detail by Blumberg and Mellor (1987) and Mellor (2004). POM is a free surface, sigma coordinate model that uses a time-splitting technique to solve depth-integrated and fully three-dimensional equations with different time steps. The surface elevation, velocity, temperature, and salinity fields are prognosticated assuming the fundamental hypotheses: i)
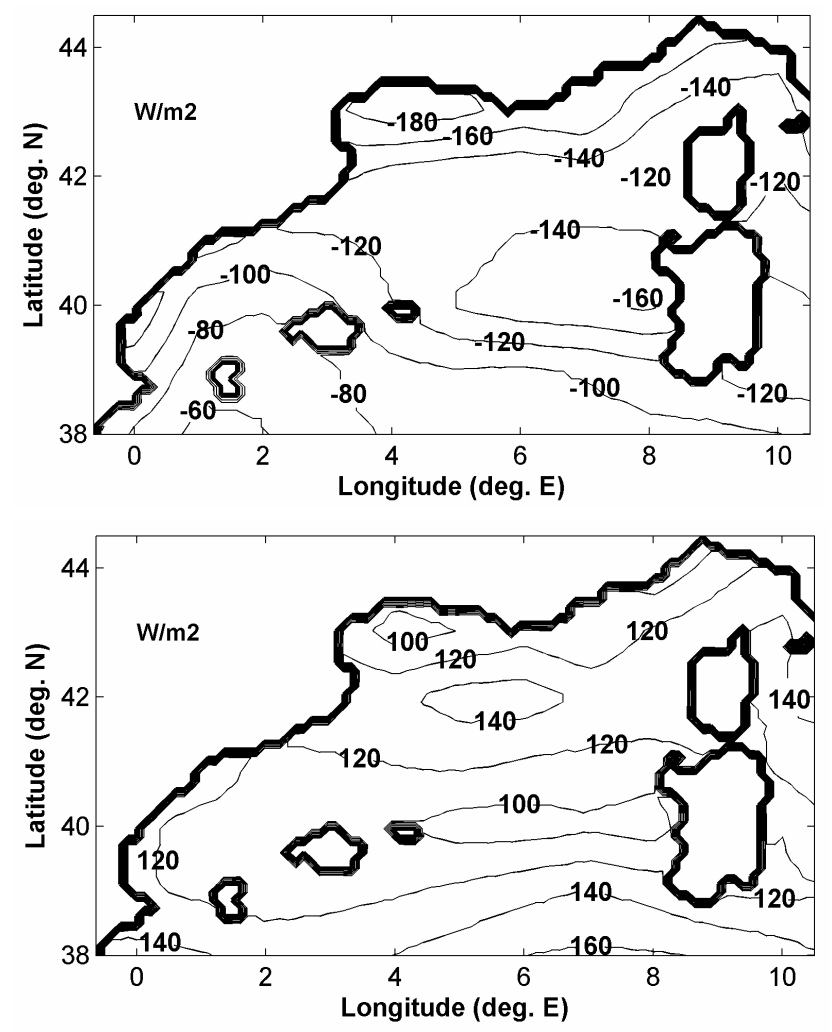

Fig. 2. Spatial distribution of Net Heat Flux from ECMWF 19791993 reanalysis data: February (upper panel) and August (lower panel). Units are $\mathrm{W} / \mathrm{m}^{2}$.

that the seawater is incompressible, ii) that the pressure in any point of the ocean is equal to the weight of the column of water over it (hydrostatic approximation), and iii) that the density can be expressed in terms of a mean value and a small fluctuation (Boussinesq's approximation). Consequently, in a system of orthogonal Cartesian coordinates, the governing equations are

$$
\begin{aligned}
& \frac{\partial U_{i}}{\partial x_{i}}=0 \\
& \frac{\partial(U, V)}{\partial t}+\frac{\partial\left[U_{i}(U, V)\right]}{\partial x_{i}}+f(-V, U)= \\
& -\rho_{0}^{-1}\left[\frac{\partial p}{\partial x}, \frac{\partial p}{\partial y}\right]+\frac{\partial\left(K_{M} \frac{\partial(U, V)}{\partial z}\right)}{\partial z} \\
& +\left(F_{U}, F_{V}\right)
\end{aligned}
$$

$\frac{\partial p}{\partial z}=-\rho g$

$\frac{\partial \theta}{\partial t}+\frac{\partial\left(U_{i} \theta\right)}{\partial x_{i}}=\frac{\partial\left(K_{H} \frac{\partial \theta}{\partial z}\right)}{\partial z}$

$\frac{\partial S}{\partial t}+\frac{\partial\left(U_{i} S\right)}{\partial x_{i}}=\frac{\partial\left(K_{H} \frac{\partial S}{\partial z}\right)}{\partial z}+F_{S}$ 

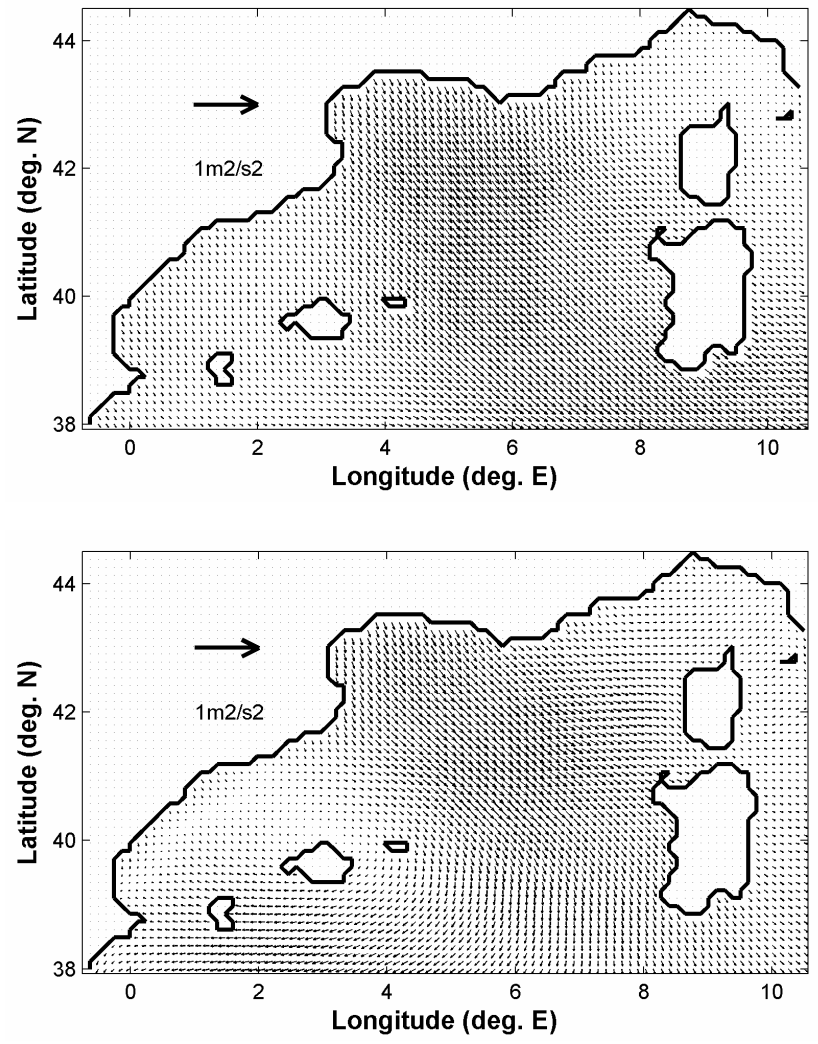

Fig. 3. Spatial distribution of Wind Stress from ECMWF 19791993 reanalysis data: February (upper panel) and August (lower panel). Units are $\mathrm{m}^{2} / \mathrm{s}^{2}$.

Vertical mixing coefficients, $K_{M}$ and $K_{H}$, are computed according to the Mellor-Yamada 2.5 turbulence closure scheme (Mellor and Yamada, 1982). This scheme requires prognostic calculations of $\left(q^{2}\right)$ and $\left(q^{2} \ell\right)$, where the turbulent kinetic energy is $q^{2} / 2$ and the turbulence macro scale is $(\ell)$. The equations that calculate $q^{2}$ and $q^{2} \ell$ are similar to those used for temperature and salinity and include production and dissipation source/sink terms. Horizontal diffusion terms $\left(F_{U}\right.$, $F_{V}, F_{\theta}$, and $F_{S}$ ) are computed using the Smagorinsky (1963) formulation, implemented into POM according to Mellor and Blumberg (1986). The last term in Eq. (4), is the solar radiation flux that penetrates the sea surface. The UNESCO equation of state, as adapted by Mellor (1991) is used. The in situ density is determined as a function of salinity, potential temperature and pressure; the latter being approximated by the hydrostatic relation and constant density.

\subsection{Model configuration}

The model domain comprises the northwestern region of the Mediterranean Sea, from $38.5^{\circ} \mathrm{N}$ to $44.5^{\circ} \mathrm{N}$ and from $0.5^{\circ} \mathrm{W}$ to $10.5^{\circ} \mathrm{E}$. The bottom topography is based on the U.S. Navy Digital Bathymetric Data Base $5\left(1 / 12^{\circ} \times 1 / 12^{\circ}\right)$ mapped onto the model domain using bilinear interpolation.
Table 1. Model Parameters used during the Climatological Experiment.

\begin{tabular}{lll}
\hline Parameter & Description & Value \\
\hline$C$ & $\begin{array}{l}\text { Non-dimensional constant used in calculating } \\
\text { the horizontal viscosity for momentum }\end{array}$ & 0.2 \\
tprni & Inverse horizontal Prandtl number & 0.2 \\
$\mu M$ & Background viscosity & 0.00002 \\
$Z_{0}$ & Bottom roughness length & 0.01 \\
$\Delta t_{\text {ext }}$ & External mode time step & $9 \mathrm{~s}$ \\
$\Delta t_{\text {int }}$ & Internal mode time step & $720 \mathrm{~s}$ \\
\hline
\end{tabular}

The resulting topography is shown in Fig. 1, which displays the major features of the domain including Sardinia, Corsica, Minorca, Majorca, and Ibiza Islands. In this model version (afterwards, NMS model) there are two open lateral boundaries; at $38.5^{\circ} \mathrm{N}$ and at $10.5^{\circ} \mathrm{E}$. The NMS model has been configured with a horizontal resolution of $1 / 16^{\circ}$ in latitude by $1 / 16^{\circ}$ in longitude, therefore with this resolution, the Rossby radius of deformation (10-20 km in the Mediterranean) is resolved, and consequently, the NMS model configuration is adequate to simulate mesoscale structures (Fernández et al., 2005). In the vertical, the grid has 27 sigma layers with logarithmic distributions at the surface and at the bottom and a linear distribution in between. Nine reduced thickness sigma layers have been laid at the surface while at the bottom there are six. Other significant model parameters are given in Table 1 .

\subsubsection{Open lateral boundary conditions}

Along the two open lateral boundaries, the NMS model is forced with velocity, salinity and temperature fields obtained from the 8th year of the Mediterranean Sea OGCM climatological integration (perpetual year run). This Mediterranean Sea model is based on the rigid lid Modular Ocean Model (MOM), which was configured with a horizontal resolution of $1 / 8^{\circ} \times 1 / 8^{\circ}$ and 31 vertical levels and it was forced by the same atmospheric data set used here. For more details about the model configuration see Demirov and Pinardi (2002), Korres and Lascaratos (2003) and Tonani (2003). Given that the NMS model has not the same horizontal resolution than the OGCM, a horizontal bilinear interpolation of the OGCM fields was necessary. Besides, as the vertical coordinate system is different, these data were transformed from z-levels to sigma coordinates using a linear interpolation. Finally, to avoid temporal discontinuities on the open lateral boundaries of the NMS model, all data are specified at each time step using a linear interpolation in time between consecutive 10-day averaged fields.

For the internal mode, velocities normal to the open lateral boundaries were directly specified from the OGCM outputs, ensuring at each time step a zero net volume transport on the boundary. To do this, we applied the procedure 

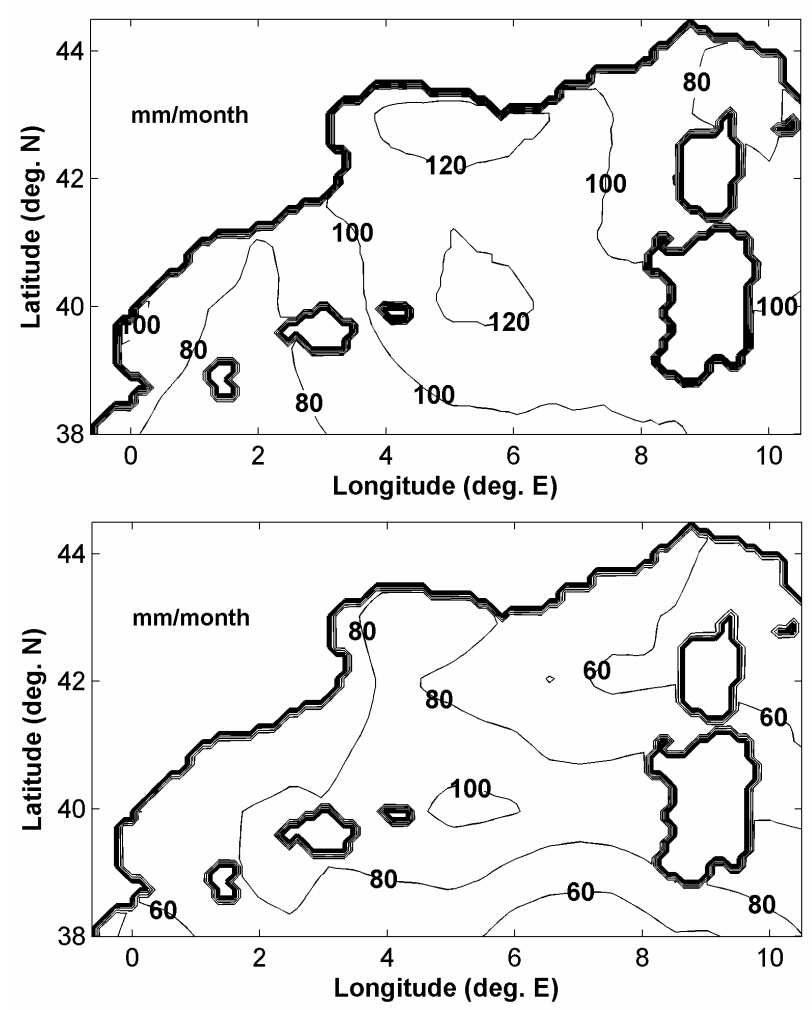

Fig. 4. Spatial distribution of Evaporation rate (E) from ECMWF 1979-1993 reanalysis data minus Precipitation $(P)$ from Legates and Willmot (1991) monthly climatology: February (upper panel) and August (lower panel). Units are $\mathrm{mm} / \mathrm{month}$.

described in detail by Zavatarelli et al. (2002), Korres and Lascaratos (2003), and Zavatarelli and Pinardi (2003). On the other hand, after several sensitivity tests to different formulations for the open lateral boundary conditions, the NMS model solution did not show overly sensitive to the velocity component tangential to the open lateral boundaries. For this reason, in this particular experiment, we set it to zero. For salinity and temperature, whenever the normal velocity is directed outwards from the NMS model's domain (outflows), the values are extrapolated from the interior solution using an upstream advection scheme. Otherwise, in cases of inflow through the boundary, salinity and temperature are prescribed from the OGCM outputs.

For the external mode, it is imposed

$$
\begin{aligned}
& (\bar{U}, \bar{V})= \\
& {[H /(H+\eta)]\left(\bar{U}_{O G C M}, \bar{V}_{O G C M}\right)}
\end{aligned}
$$

where $\bar{U}$ and $\bar{V}$ are the vertically integrated velocities on the NMS model's open lateral boundaries, $H$ is the bottom depth, $\eta$ is the free-surface elevation, and $\bar{U}_{\mathrm{OGCM}}$ and $\bar{V}_{\mathrm{OGCM}}$ are the vertically integrated velocities from the OGCM outputs. The ratio $H /(H+\eta)$ is employed to ensure the volume continuity (Korres and Lascaratos, 2003; Zavatarelli et
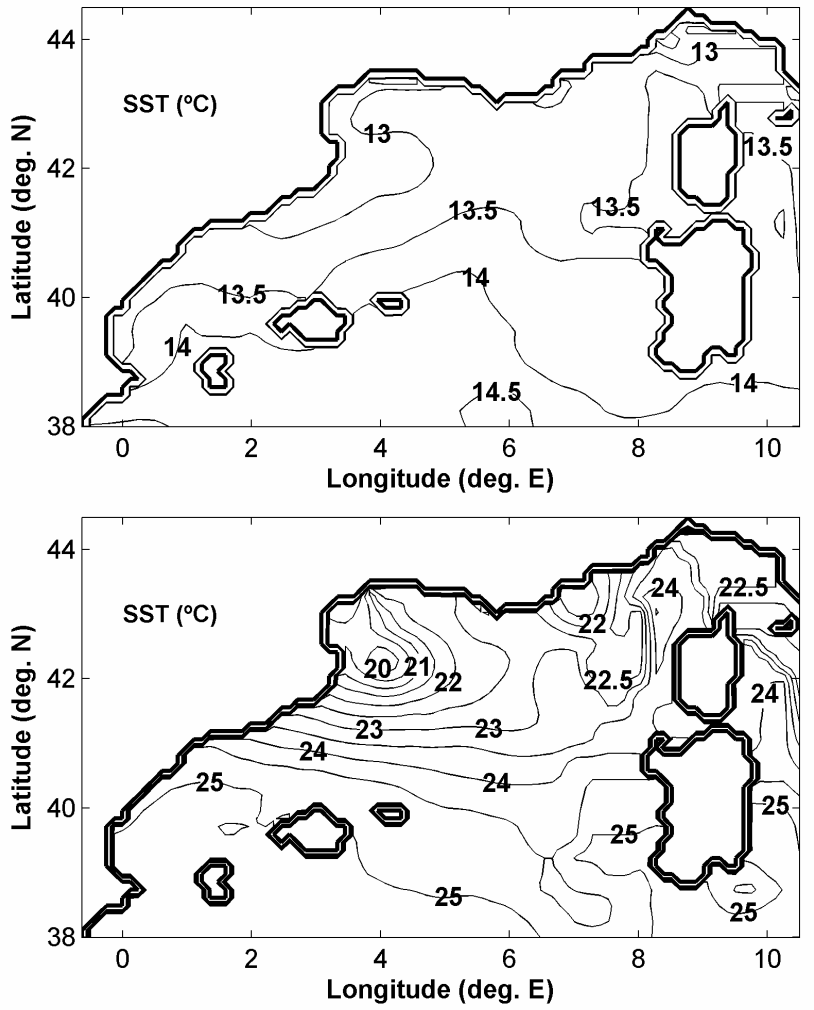

Fig. 5. Sea Surface Temperature (SST) from MED6 monthly climatology: February (upper panel) and August (lower panel). The contour interval is $0.5^{\circ} \mathrm{C}$.

al., 2002, 2003). Finally, tangential velocities were set to zero and a zero-gradient condition for the free-surface elevation was used.

\subsubsection{Surface boundary conditions}

All atmospheric forcing (wind stress, heat flux and freshwater flux components) are mapped onto the NMS model grid using bilinear interpolation. Additionally, during the model integration, the atmospheric forcing is specified at each external or internal time step, using linear interpolation in time between successive fields. So, the surface boundary condition for momentum is prescribed according to

$\frac{K_{M}}{D}\left(\frac{\partial(u, v)}{\partial \sigma}\right)=-\rho_{0}^{-1}\left(\tau_{x}, \tau_{y}\right)$

where $\tau_{x}$ and $\tau_{y}$ represent the surface wind stress components obtained from the European Center for MediumRange Weather Forecasts (ECMWF) 1979-1993, 6-h reanalysis data on a regular $1^{\circ}$ by $1^{\circ}$ grid (for more details about these data, see Korres and Lascaratos, 2003) and $\rho_{0}$ is the density of reference taken as $1025 \mathrm{~kg} \mathrm{~m}^{-3}$ (Mellor, 2004).

For temperature the following formulation is used

$\frac{K_{H}}{D}\left(\frac{\partial \theta}{\partial \sigma}\right)=\frac{Q_{T}}{\rho_{0} C_{p}}$

$+\frac{C_{1}}{\rho_{0} C_{p}}(S S T-T)$ 

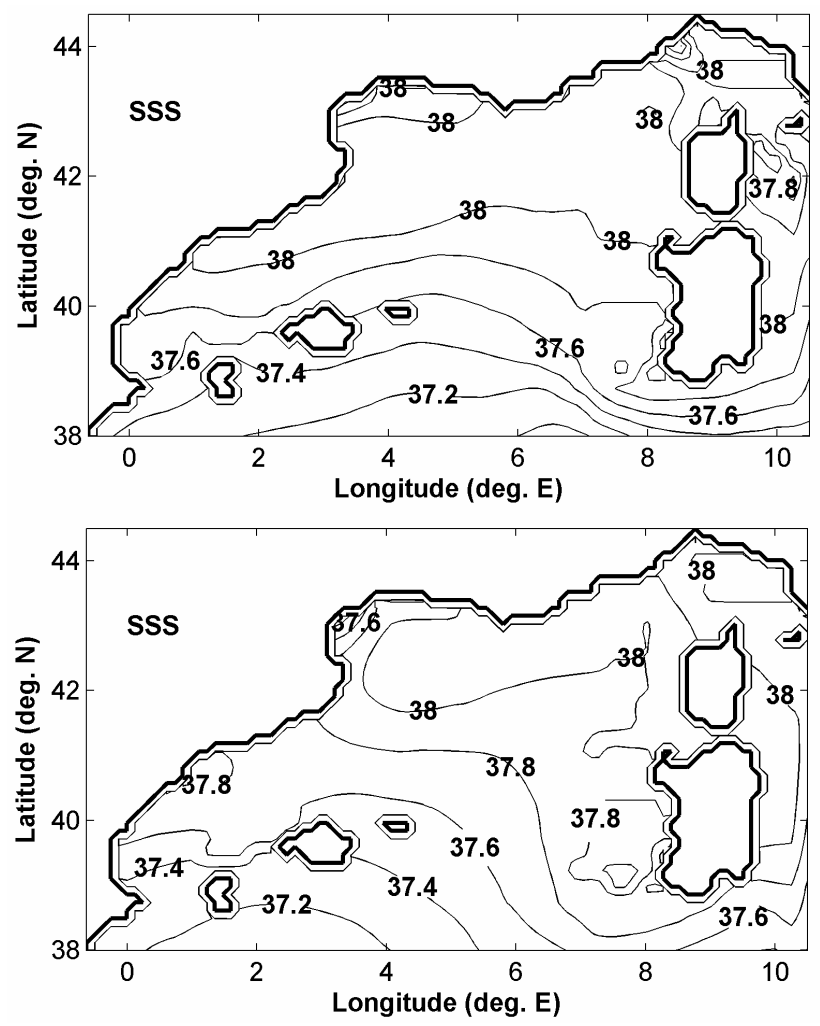

Fig. 6. Sea Surface Salinity (SSS) from MED6 monthly climatology: February (upper panel) and August (lower panel). The contour interval is 0.2 .

where $Q_{T}$ represents the total heat flux and $C_{p}$ the specific heat of seawater, $3986 \mathrm{Jkg}^{-1}$ (Mellor, 2004). The second term in Eq. (8) is the heat flux correction term, where $S S T$ is the sea surface temperature obtained from the MED6 monthly climatology, $T$ is the temperature at the first layer of the NMS model, and $C_{1}$ is a coefficient taken as $15 \mathrm{Wm}^{-2 \circ} \mathrm{C}^{-1}$. In this way the heat flux is forced to produce a sea surface temperature consistent with the MED6 monthly climatology (Sorgente et al., 2003).

For salinity the surface boundary condition is given according to

$\frac{K_{H}}{D}\left(\frac{\partial S}{\partial \sigma}\right)=\left(\frac{E-P}{\rho_{0}}\right)+C_{2}(S S S-S)$

where $E$ corresponds to the monthly evaporation rate calculated according to $E=Q_{E} / L_{V}$ (Zavatarelli and Mellor, 1995; Korres and Lascaratos, 2003; Sorgente et al., 2003), $P$ is the monthly precipitation obtained from Legates and Willmot (1991). The second term in Eq. (9) is the freshwater flux correction term, where $S S S$ is the sea surface salinity obtained from the MED6 monthly climatology, $S$ is the salinity at the first layer of the NMS model, and $C_{2}$ is a coefficient taken as $0.7 \mathrm{~m} /$ day. The correction term accounts for the imperfect knowledge of $E-P$, especially of $P$ (Sorgente et al., 2003).
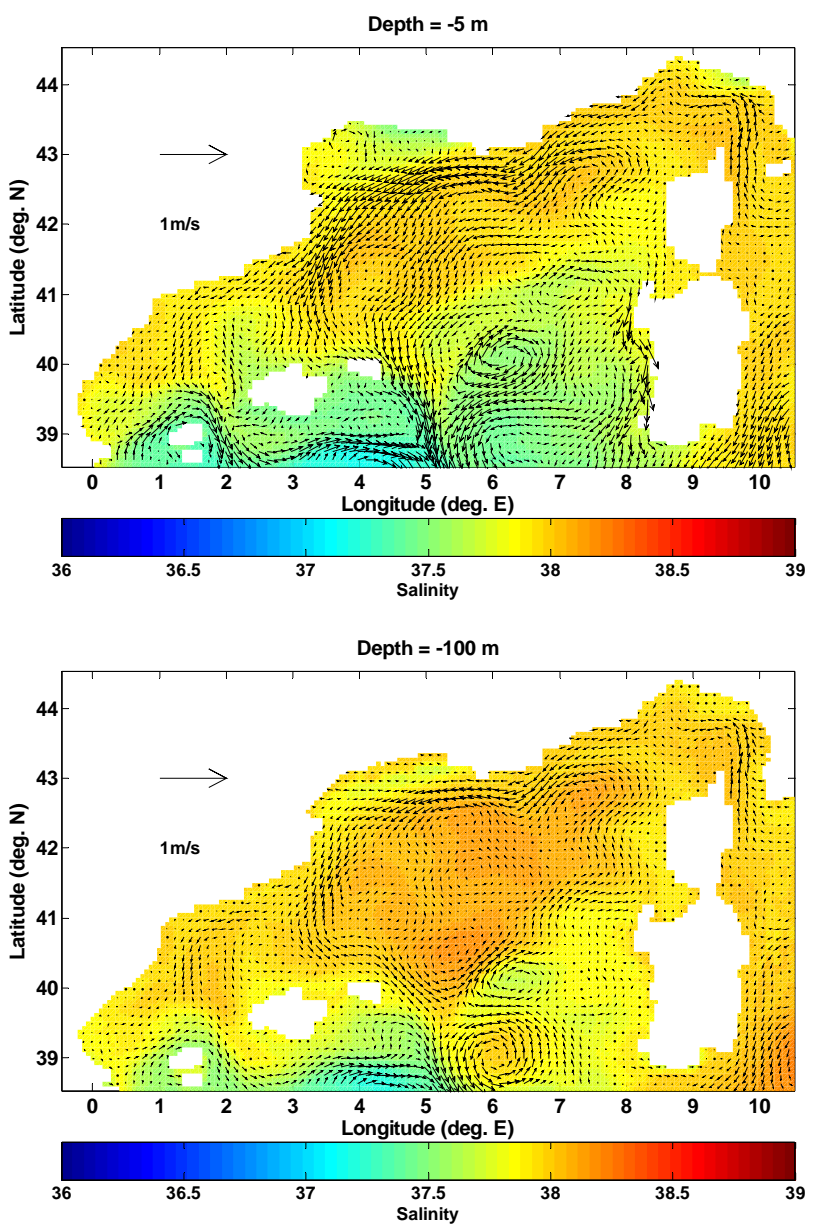

Fig. 7. Initial Conditions for velocity and salinity: at 5-m depth (upper panel) and at 100-m depth (lower panel), from December of the 8th year of the Mediterranean Sea OGCM climatological integration (source data: Mediterranean Forecasting System, 2002).

Finally, where the Rhone and the Ebro rivers discharge their waters an additional term is included in the surface boundary condition for salinity so that the first term on the right side of Eq. (9) is considered as $\left(E-P-R_{i}\right) / \rho_{0}$, where $\mathrm{R}_{i}$ represents the river runoffs in $\mathrm{ms}^{-1}$.

Finally, for the turbulence kinetic energy and the turbulence master length scale, the surface boundary condition is prescribed according to Mellor (2004).

\subsubsection{Bottom boundary conditions}

The bottom boundary conditions for momentum, salinity, temperature, turbulence kinetic energy and the turbulence master length scale, are set according to Mellor (2004). 

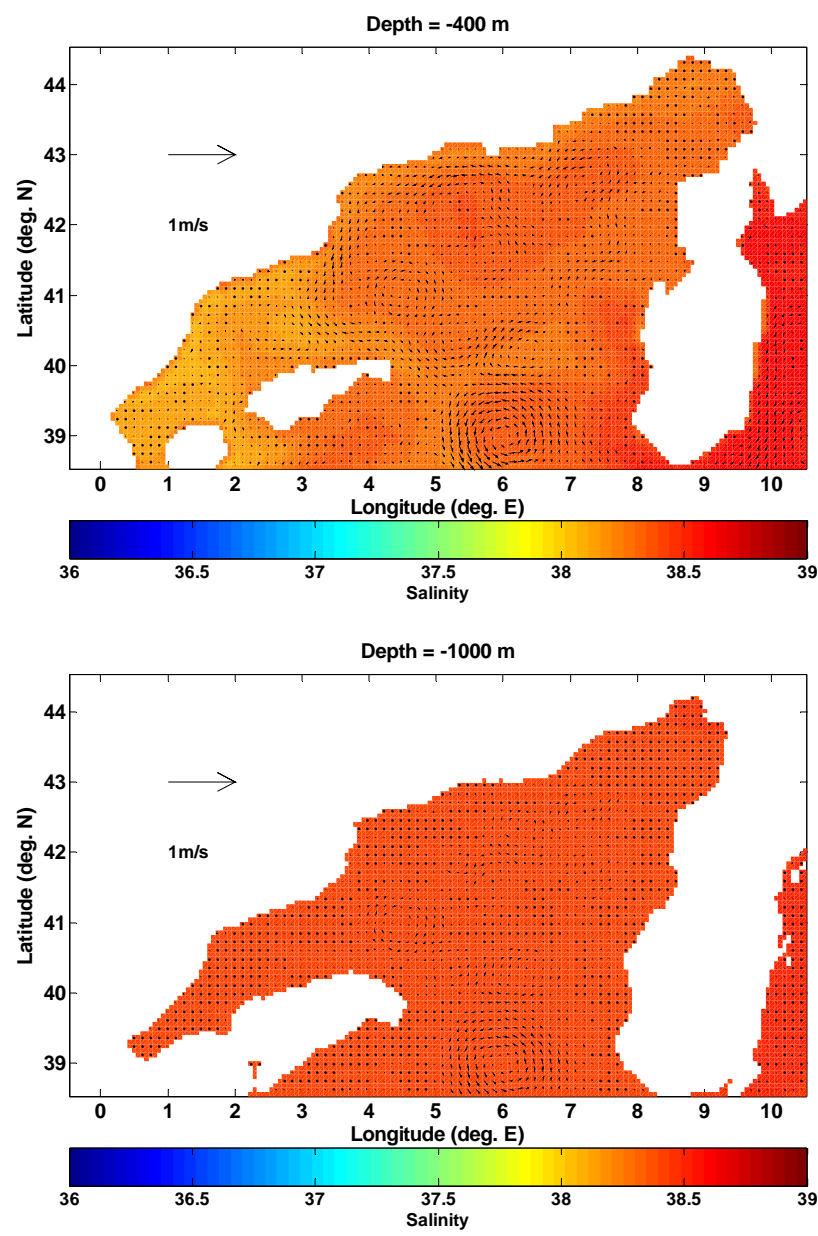

Fig. 8. Initial Conditions for velocity and salinity: at 400-m depth (upper panel) and at 1000-m depth (lower panel), from December of the 8th year of the Mediterranean Sea OGCM climatological integration (source data: Mediterranean Forecasting System, 2002).

\section{Model forcing and initial conditions}

\subsection{Model forcing}

\subsubsection{Heat fluxes}

The spatial distribution of the net heat flux in the NMS model's domain for a typical winter (February) and summer (August) month is shown in Fig. 2. During February heat is lost throughout the domain, especially over the Gulf of Lions, the Ligurian Sea and along the west coast of Sardinia. In contrast, during August heat is gained everywhere, particularly in the Gulf of Lion cyclonic gyre, over the southern part of the Ligurian Sea and along the southern boundary of the NMS model's domain. In general, there is a meridional (south-north) gradient, more evident in February but less in August.
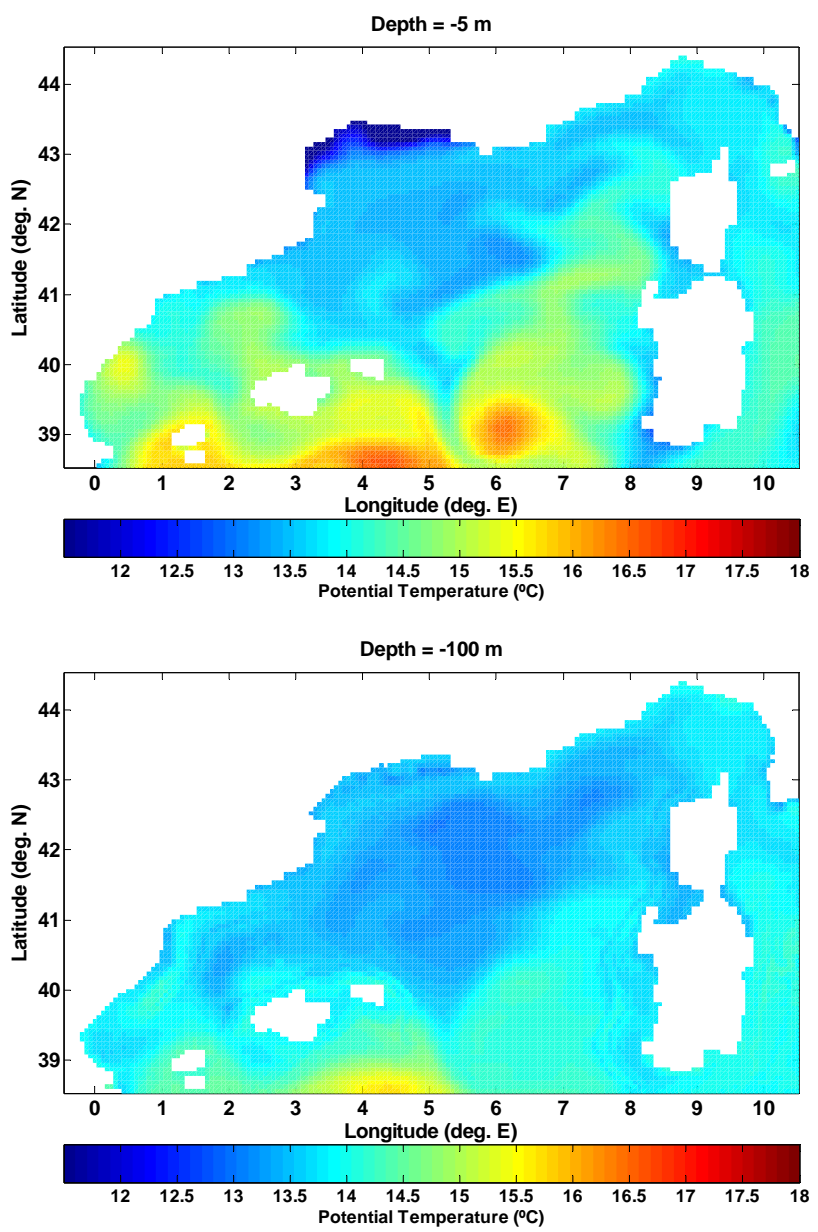

Fig. 9. Initial Conditions for potential temperature: at 5-m depth (upper panel) and at 100-m depth (lower panel), from December of the 8th year of the Mediterranean Sea OGCM climatological integration (source data: Mediterranean Forecasting System, 2002).

\subsubsection{Wind stress}

The climatological wind stress fields for February and August are shown on Fig. 3. The most prominent feature during these months is the incidence of winds blowing from northwest, mostly over the central region of the NMS model's domain and over the Catalan Sea. These winds are clearly more intense in a perpendicular line to the Gulf of Lions, weakening toward the Catalan Sea. In contrast, on the Ligurian Sea the winds are comparatively less strong, following a path nearly anticyclonic in August, while in February they practically blow from north. It is also evident that the mountain ranges in the Balearic Islands, Sardinia, and Corsica play an important role in the final trajectory of these winds, which shows a very clear curvature on the south side of the Balearic Islands and on the east side of Sardinia and Corsica. In $\mathrm{Au}-$ gust, the winds describe an almost cyclonic trajectory in the Balearic Islands region, which disappears in February. On 

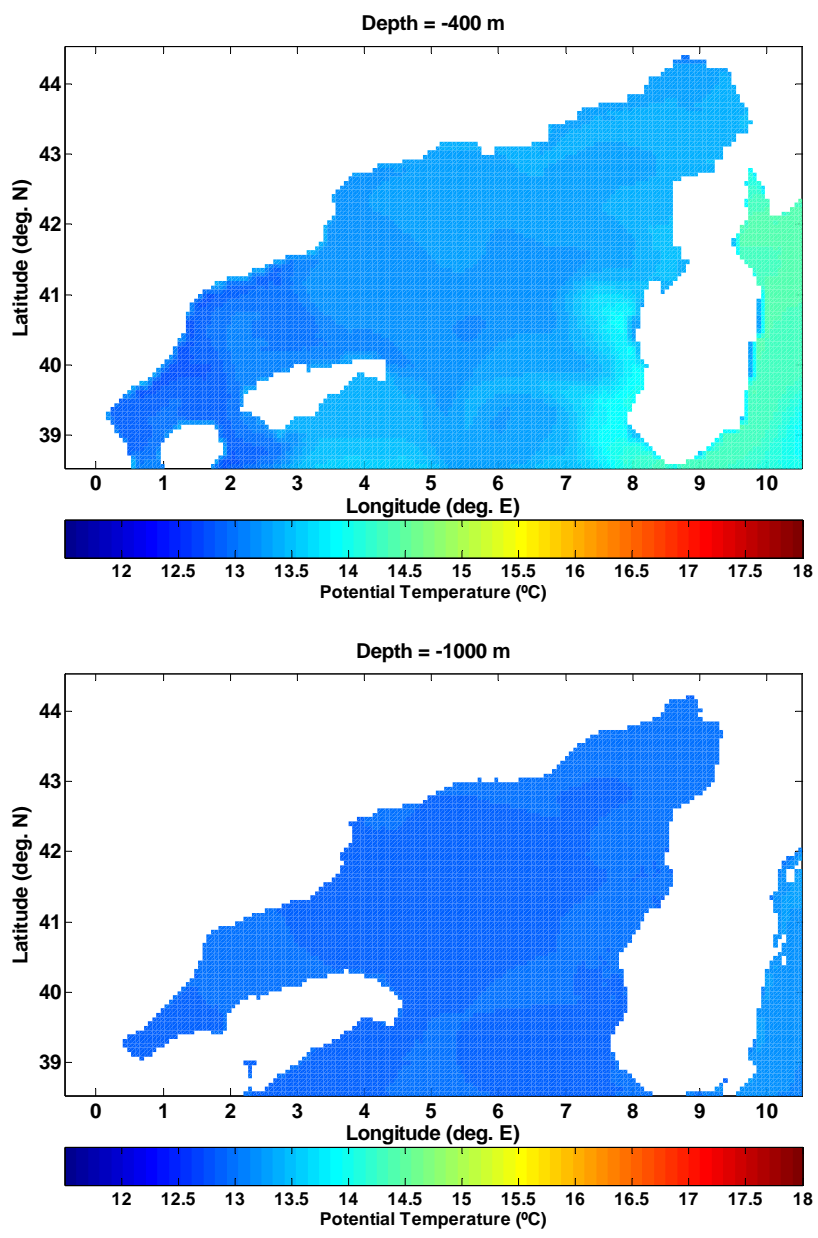

Fig. 10. Initial Conditions for potential temperature: at 400-m depth (upper panel) and at 1000-m depth (lower panel), from December of the 8th year of the Mediterranean Sea OGCM climatological integration (source data: Mediterranean Forecasting System, 2002).

the other hand, the winds over the eastern region of Sardinia and Corsica blow eastward during both months. In general, the climatological winds are more intense during February than during August.

\subsubsection{Evaporation rate minus precipitation}

The spatial distribution of evaporation rate minus precipitation (E-P) for February and August is shown in Fig. 4. This figure illustrates the freshwater losses affecting the entire NMS model's domain, especially intense in the Gulf of Lions and between Minorca and Sardinia. During February there is a clear southwest-northeast gradient, while during August this gradient is not so well defined.

\subsubsection{Sea surface temperature and salinity}

The sea surface temperature and salinity from the MED6 monthly climatology for February and August are shown in
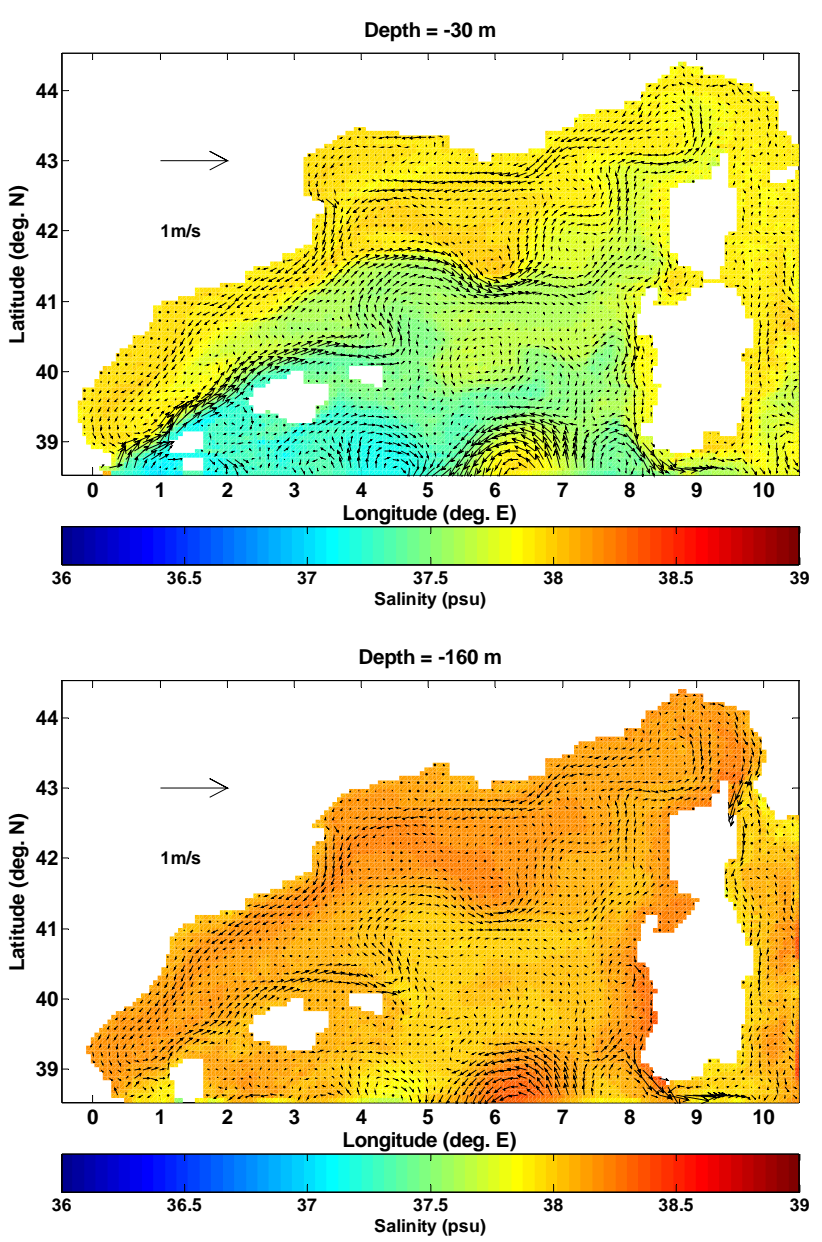

Fig. 11. Velocity field and horizontal distribution of salinity: at 30-m depth (upper panel) and at 160-m depth (lower panel) during August from the climatological experiment.

Figs. 5 and 6. The sea surface thermal structure over the NMS model's domain in February is moderately homogeneous, particularly in the northern area that extends from the Balearic Islands to the Ligurian Sea. In this region, the temperature does not exceed $13.5^{\circ} \mathrm{C}$. The coldest waters $\left(13^{\circ} \mathrm{C}\right)$ are found on the Ligurian Sea, Gulf of Lions and the north part of the Catalan Sea. In contrast, the warmer waters $\left(14^{\circ}-\right.$ $14.5^{\circ} \mathrm{C}$ ) are found over the whole southern part of the domain. During August, this thermal structure clearly changes reaching temperatures between $20^{\circ} \mathrm{C}$ (particularly over the Gulf of Lions) and $25^{\circ} \mathrm{C}$ (on the south side of the NMS model's domain). In this month, the Ligurian Sea shows temperatures from $22^{\circ}$ to $24^{\circ} \mathrm{C}$, while on the east side of Sardinia and Corsica temperatures between $24^{\circ}$ and $25^{\circ} \mathrm{C}$ are found. Also, in this month, a meridional gradient is evident with temperatures decreasing northward. Concerning the sea surface salinity, during February and August, the NMS model's domain presents the following characteristics: 1) a meridional gradient with salinity values increasing northward, 2) 

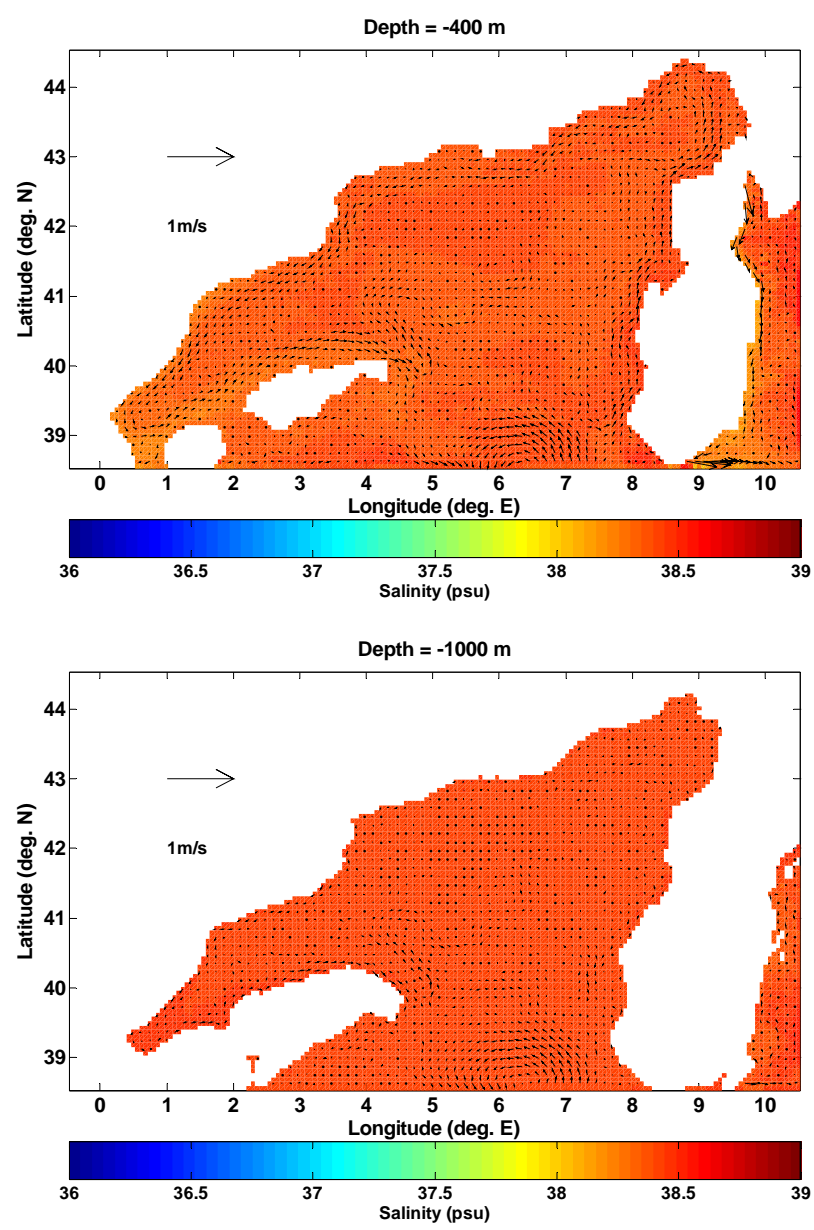

Fig. 12. Velocity field and horizontal distribution of salinity: at 400$\mathrm{m}$ depth (upper panel) and at 1000-m depth (lower panel) during August from the climatological experiment.

salinity values between 37.2 and 37.8 over the southern region (between $\sim 38.5^{\circ}$ and $41^{\circ} \mathrm{N}$ ), and 3) salinity values of 38 on the region north of $41^{\circ} \mathrm{N}$. In the latter, the exceptions are the Gulf of Lions shelf and the west part of the Ligurian Sea where salinities of 37.8 are observed. From a seasonal point of view, the sea surface salinity on the NMS model's domain does not show significant variations from one month to another. However, it is evident that waters with salinities between 37.6 and 37.8 invade the northern region mainly in August.

\subsubsection{River runoffs}

According to the Compagnie Nationale du Rhône (Younes et al., 2003), the Rhone River runoffs, from 1996 to 2000, varied from a monthly average maximum of $2522 \mathrm{~m}^{3} \mathrm{~s}^{-1}$ (December) to a minimum $943 \mathrm{~m}^{3} \mathrm{~s}^{-1}$ (August) with an annual mean value of $1745 \mathrm{~m}^{3} \mathrm{~s}^{-1}$. During the same period, the Ebro River annual mean runoffs; obtained from the Confederación Hidrográfica del Ebro (Jordà, 2005), was $315 \mathrm{~m}^{3} \mathrm{~s}^{-1}$, with
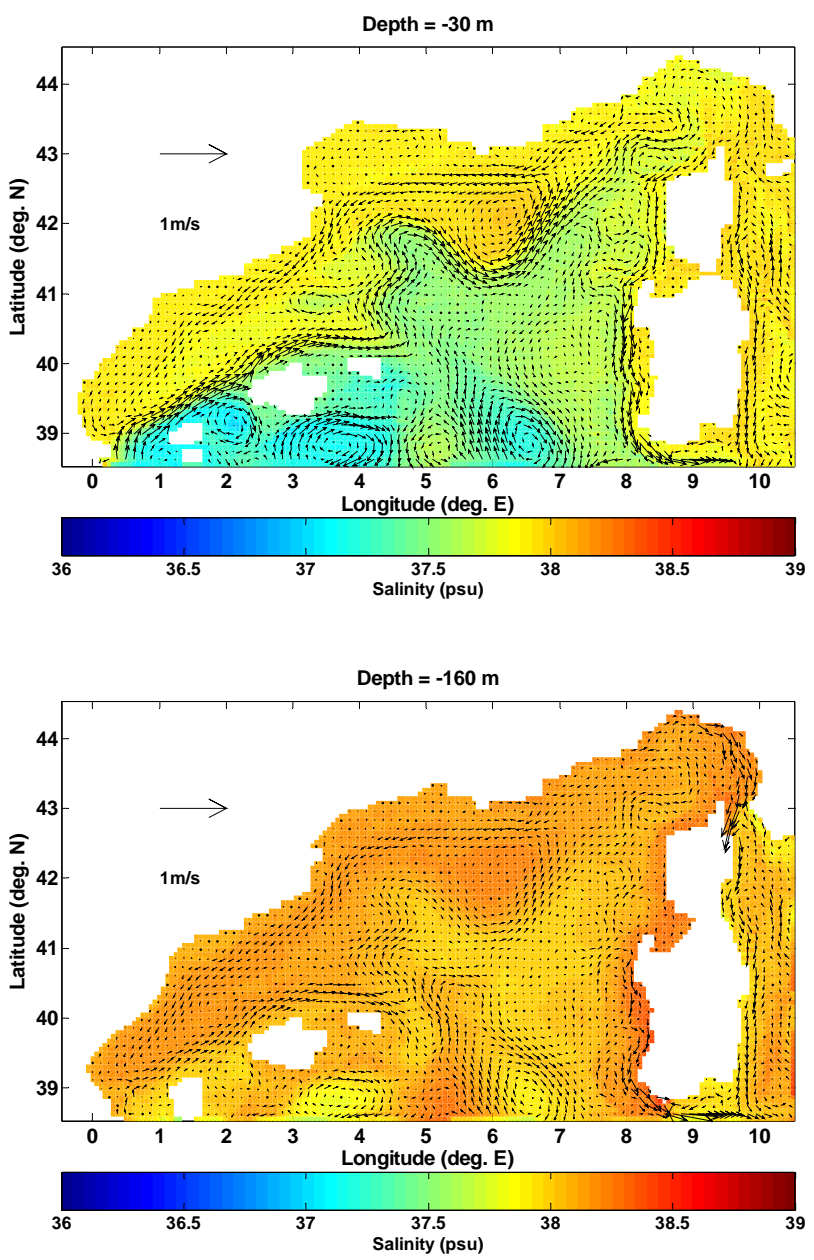

Fig. 13. Velocity field and horizontal distribution of salinity: at 30-m depth (upper panel) and at 160-m depth (lower panel) during November from the climatological experiment.

a monthly average maximum of $689 \mathrm{~m}^{3} \mathrm{~s}^{-1}$ (January) and a minimum of $128 \mathrm{~m}^{3} \mathrm{~s}^{-1}$ (August).

\subsection{Initial conditions}

According to the 8th year of the Mediterranean Sea OGCM perpetual year run, the large-scale circulation in the northwestern Mediterranean is dominated by a large cyclonic gyre, which is more evident below the sea surface (Figs. 7 and 8). The Eastern Corsican Current and the Northern Current appear reasonably well defined while the Western Corsican Current is reproduced relatively far from the west coast of Corsica and the North Balearic Current is only represented to the north of Ibiza. On the other hand, the mesoscale structure is represented by some eddies reproduced inside the large cyclonic gyre and mainly on the southern region (between $38^{\circ} \mathrm{N}$ and $\sim 40^{\circ} \mathrm{N}$ ) of the NMS model's domain. Concerning the horizontal distribution of salinity illustrated also in Figs. 7 and 8, the initial conditions show a gradient 

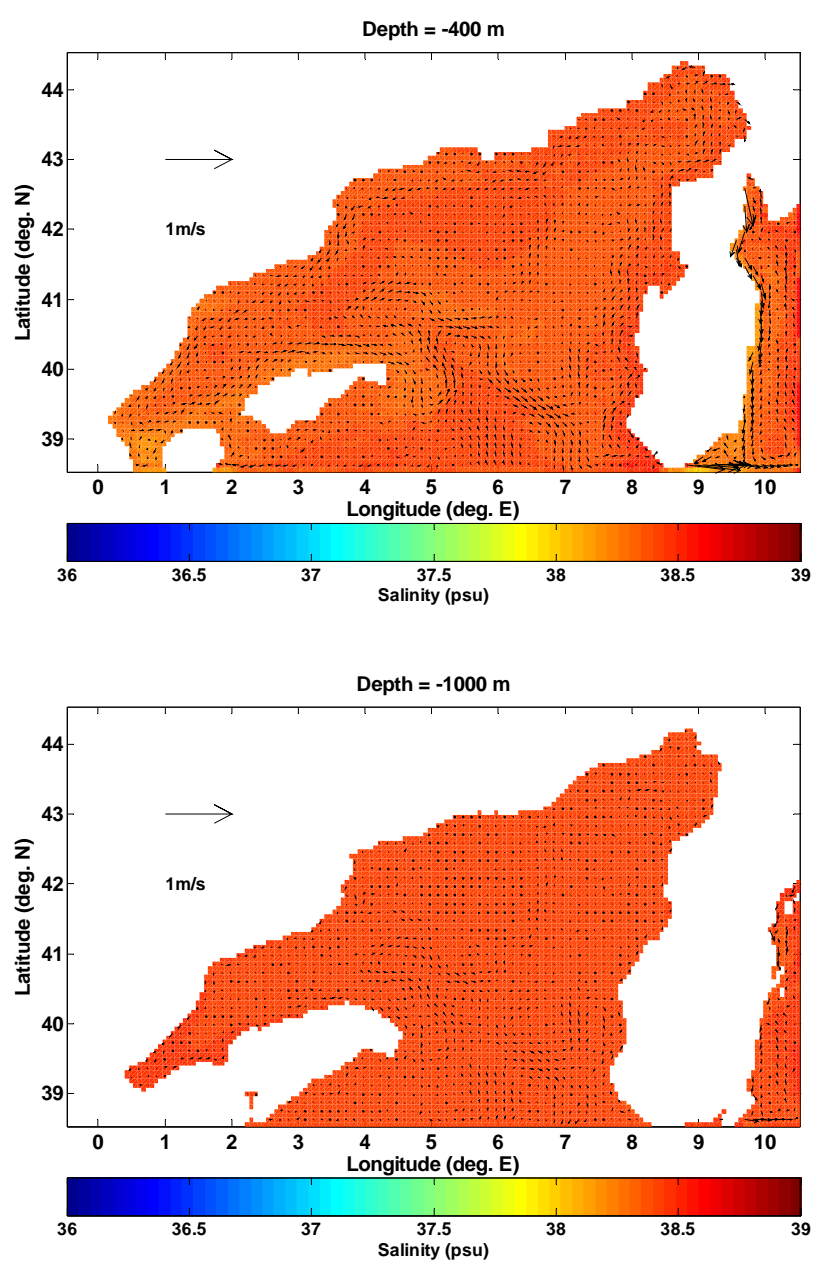

Fig. 14. Velocity field and horizontal distribution of salinity: at 400$\mathrm{m}$ depth (upper panel) and at 1000-m depth (lower panel) during November from the climatological experiment.

approximately latitudinal with higher salinity values at the northern areas, especially inside the large cyclonic gyre. In contrast, the western part of the Tyrrhenian Sea does not show this latitudinal gradient but its salinity values are comparable to those inside the cyclonic gyre. On the other hand, the horizontal distribution of potential temperature (Figs. 9 and 10) shows the lower values (between $\sim 13-14^{\circ} \mathrm{C}$ ) over the northern part of the Catalan Sea, the Gulf of Lions, the Ligurian Sea and particularly, inside the large cyclonic gyre. In contrast, the higher temperatures (between $\sim 14.5-17^{\circ} \mathrm{C}$ ) are observed on the southern part of the NMS model domain, including the southwestern area of the Tyrrhenian Sea.

\section{Model results and discussions}

In the following paragraphs the NMS model results for a typical summer (August), autumn (November), winter (February) and spring (May) month will be analyzed. These re-
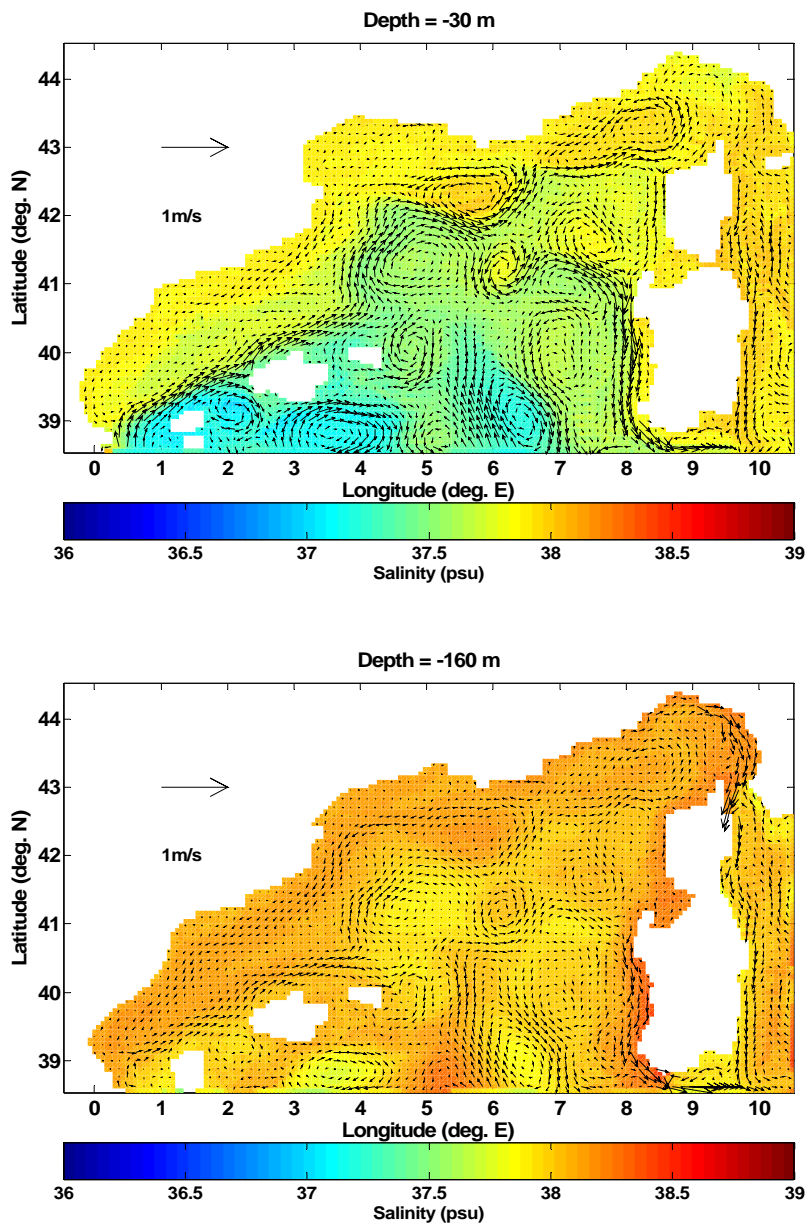

Fig. 15. Velocity field and horizontal distribution of salinity: at 30-m depth (upper panel) and at 160-m depth (lower panel) during February from the climatological experiment.

sults correspond to the climatological integration of the NMS model, which was run for 12 years with forcing and initial conditions described in Sect. 3 and model parameters summarized in Table 1.

According to this climatological experiment, during August the northern part of the NMS model's domain is characterized by a well-defined large-scale cyclonic circulation at least up to 400-m depth (Fig. 11 and Fig. 12, upper panel). In this month, there is clear evidence of the Gulf of Lions cyclonic gyre centered at $42^{\circ} \mathrm{N}-5^{\circ} \mathrm{E}$ and the Northern Current (NC) fed by the eastern Corsican Current (ECC) and the western Corsican Current (WCC) coming from the eastern and the western side of Corsica, respectively. The NC flows along the continental slope of the Liguria, Provence, Languedoc, Catalonia, and as far as the Gulf of Valencia, where it veers eastwards following the continental slope of the Balearic Islands. In this area, the so-called North Balearic Current (in this simulation especially intense probably as a result of the strong difference between the salinity to the 

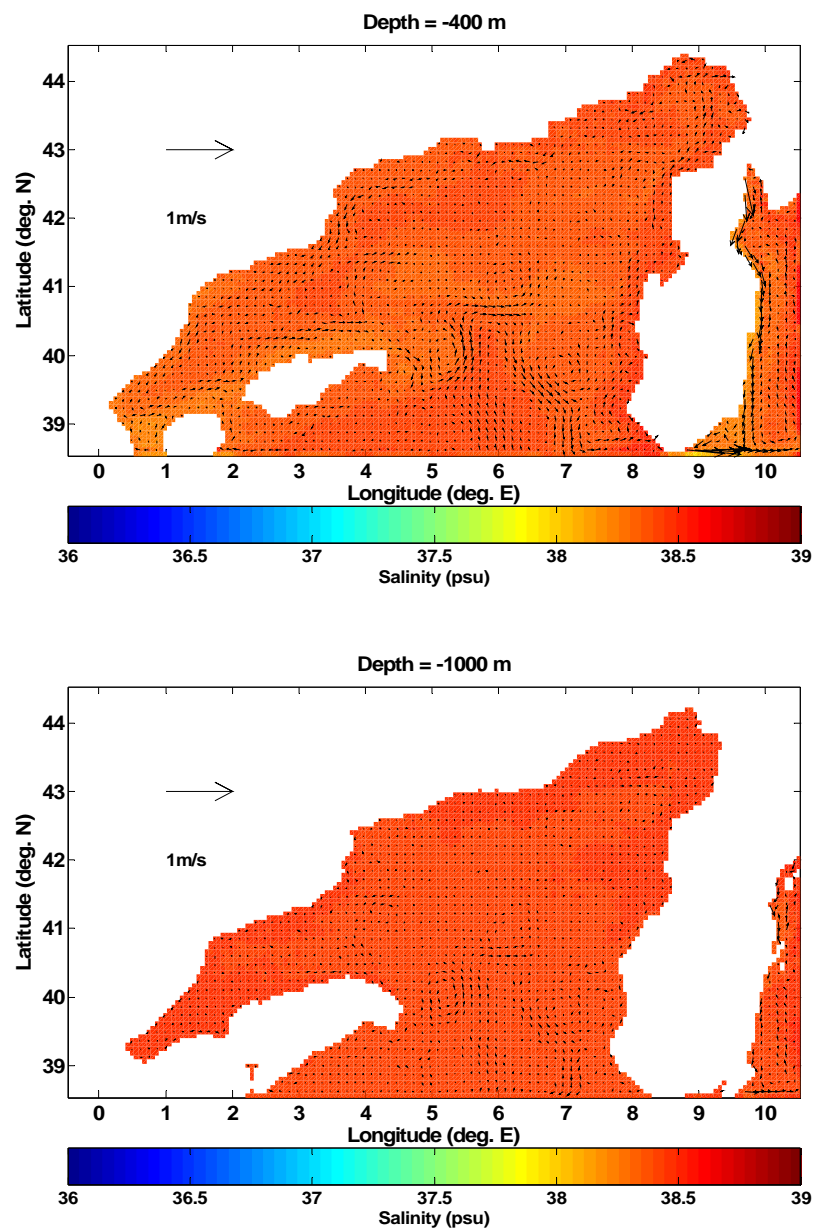

Fig. 16. Velocity field and horizontal distribution of salinity: at 400$\mathrm{m}$ depth (upper panel) and at 1000-m depth (lower panel) during February from the climatological experiment.

south and to the north of the Balearic Islands), appears as a continuous northeastwards flow closing the cyclonic circulation that is delimited southward by an oceanic front. In contrast, the southern region of the NMS model's domain is dominated principally by mesoscale eddies with different sign and dimension. These eddies, as it can be seen from the distribution of salinity, appear to play an important role in the advection of water of Atlantic origin towards the north. Concerning the circulation over the part of the Tyrrhenian Sea considered in this study, there is indication that, in the upper layers (see Fig. 11, upper panel) the flow is mainly northwards while it is southwards in the lower layers (see Fig. 11, lower panel and Fig. 12) along the Corsican and Sardinian coasts. In general, it is evident that Levantine Intermediate Water (LIW) (Fig. 12, upper panel) and Western Mediterranean Deep Water (WMDW) (Fig. 12, lower panel), possibly constrained by the bottom topography, follow essentially a cyclonic path.

During November the large-scale cyclonic circulation is
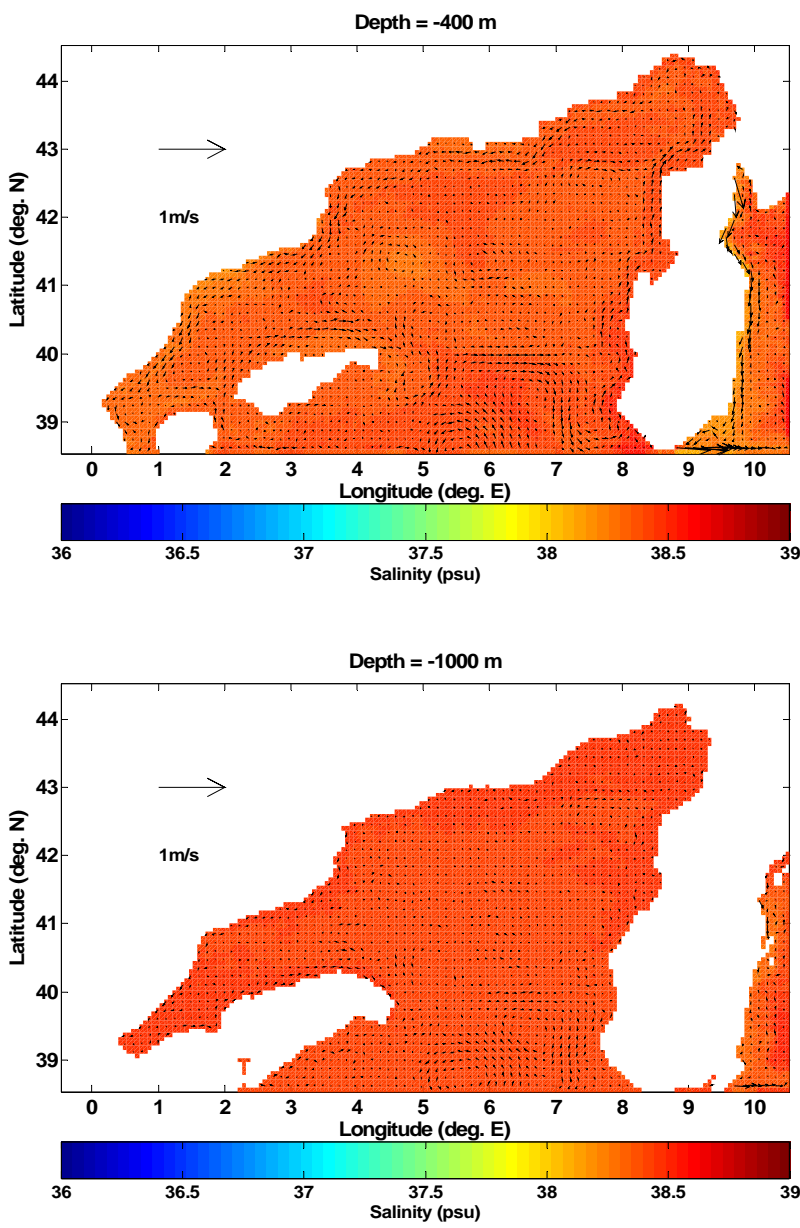

Fig. 17. Velocity field and horizontal distribution of salinity: at 30$\mathrm{m}$ depth (upper panel) and at 160-m depth (lower panel) during May from the climatological experiment.

basically the same as in August but, in this case, a stretching around $42^{\circ} \mathrm{N}-4^{\circ} 45^{\prime} \mathrm{E}$ is displayed (Fig. 13). This stretching, observed as a large meander invading the northern part, appears to be associated with the Gulf of Lions cyclonic gyre, which is relatively well-defined. Other significant features in this month are the presence of several mesoscale eddies along the western side of the Corsica and the occurrence of a cyclonic gyre on the western Tyrrhenian Sea, specifically to the north of the Strait of Bonifacio. Over the southern region of the NMS model's domain, mesoscale eddies are as in August the most important dynamic characteristic. In general, also during November, the LIW (Fig. 14, upper panel) and WMDW (Fig. 14, lower panel) follow a cyclonic path.

In February, several differences in the large scale circulation and mesoscale structure are evident. At 30-m depth (Fig. 15; upper panel) the large-scale cyclonic circulation appears relatively less coherent than in the previous months but, at 160-m depth (Fig. 15; lower panel), it is fairly similar. During this month, the NC is comparatively less intense 

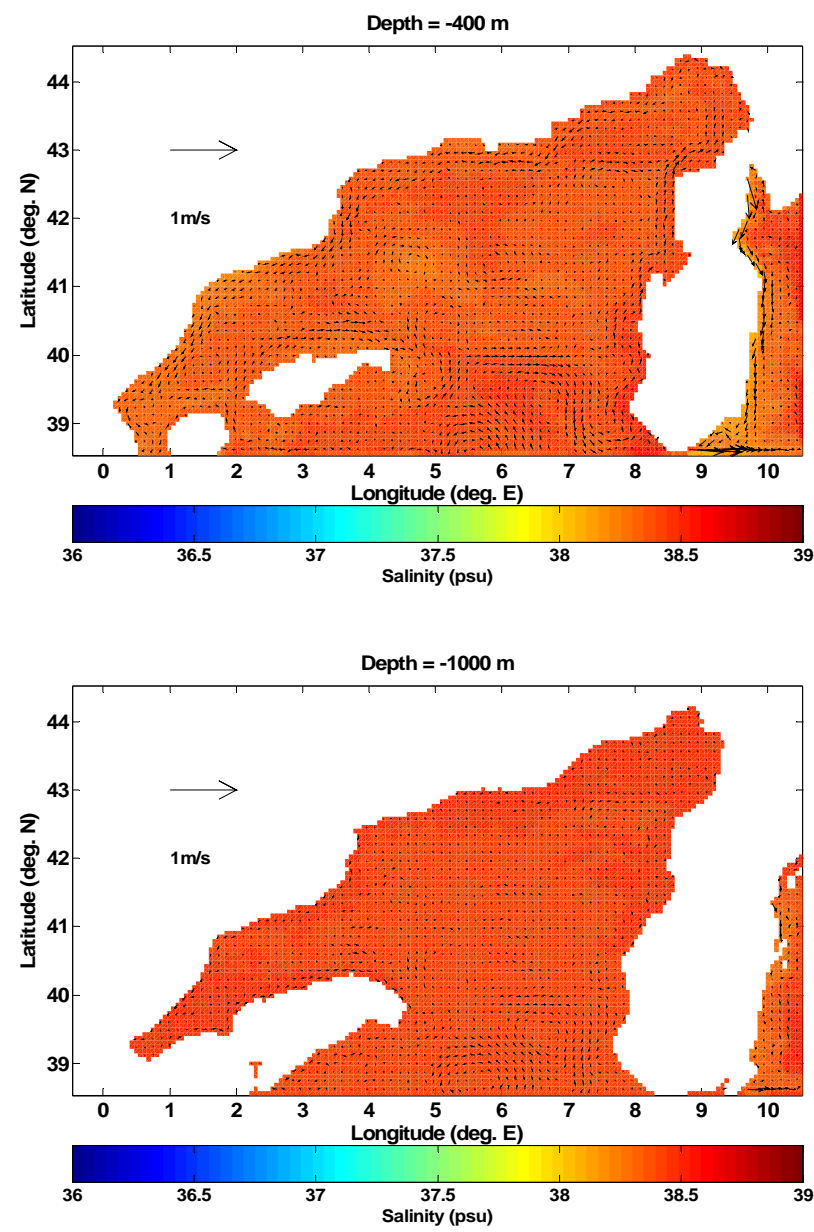

Fig. 18. Velocity field and horizontal distribution of salinity: at 400$\mathrm{m}$ depth (upper panel) and at 1000-m depth (lower panel) during May from the climatological experiment.

and three large gyres are displayed on the Ligurian Sea and offshore the Gulf of Lions where a large anticyclonic gyre closes to the Gulf of Lions cyclonic gyre is present. Furthermore, mesoscale eddies detected up to 160 -m depth prevail over the entire southern region, with evident effect, at least in the upper layer, on the southern part of the large-scale cyclonic circulation. Also, in this season, the cyclonic gyre on the western side of the Tyrrhenian Sea is present. Below this depth, the LIW (Fig. 16, upper panel) and WMDW (Fig. 16, lower panel) follow, as in August and November, essentially a cyclonic path.

Finally, during May, at 30-m depth (Fig. 17, upper panel), the NC becomes relatively more intense than in February but even less strong than during August and November. In this month, although the large gyres in the Ligurian Sea and in the Gulf of Lions open sea are less evident, the large scale cyclonic circulation is not completely reestablished. In addition, over the southern part of the Catalan Sea, meanders and mesoscale eddies have been developed. Furthermore, on the southern region of the NMS model's domain, the number of mesoscale eddies have diminished and the cyclonic gyre on the western side of the Tyrrhenian Sea has disappeared. At 160-m depth (Fig. 17, lower panel), the large-scale cyclonic circulation is basically as in the previous months but, mesoscale eddies have almost disappeared from the southern region of the NMS model's domain. Below this depth, the circulation of both LIW (Fig. 18, upper panel) and WMDW (Fig. 18, lower panel) is also cyclonic.

From these results, it is evident that the circulation in the Northwestern Mediterranean Sea is more complicated than that published by early works (among other, Nielsen, 1912; Allain, 1960, Furnestin, 1960; Wüst, 1961; Ovchinnikov, 1966). In this context, recent studies (WMCE Group, 1994; EUROMODEL Group, 1995) have pointed out that because of scarcity and spacing of ocean stations, early studies of the area have presented a simple pattern of the circulation, which is more complex and driven by a combination of factors and time scales. Several observational studies carried out in the nineties (Send et al., 1999) and during the last years have showed evidence of important mesoscale activity (fronts, meanders, eddies, filaments, etc.) affecting the circulation at local, sub-basin and basin scale. More recently, in order to investigate if the intrinsic ocean variability could be a source of interannual variability, Fernández et al. (2005) implemented an eddy permitting rigid lid ocean model (the DieCAST model) in the whole Mediterranean Sea. The model results showed the seasonality of some currents, an important eddy field and numerous fronts distributed all over the Mediterranean Sea. In the present study, an eddy permitting free surface ocean model (the POM model) forced at the surface with climatological heat fluxes and wind stress, and on the open lateral boundaries with temperature, salinity and velocity fields obtained from a Mediterranean Sea general circulation model, has confirmed that: 1) the large-scale cyclonic circulation in the Northwestern Mediterranean Sea changes from one season to another; 2) the mesoscale structure is, during all year, a significant characteristic in this region of the Mediterranean Sea, and 3) the circulation of Levantine Intermediate Water (LIW) and Western Mediterranean Deep Water (WMDW) is basically cyclonic during all year.

\section{Conclusions}

It is concluded that the large-scale cyclonic circulation in the northern part of the Northwestern Mediterranean is, at least in the upper layers, less coherent in winter and spring than in summer and autumn. It is also concluded that the mesoscale structure (eddies and meanders) is, during all year, a significant dynamic characteristic in this region of the Mediterranean Sea. Concerning the circulation in the lower layers, it is concluded that Levantine Intermediate Water and Western Mediterranean Deep Water follow essentially a cyclonic path during all year. 
Acknowledgements. We acknowledge the Mediterranean Forecasting System (MFS) for providing data for this study and several of the participants in projects MFSPP and MFSTEP for providing advice. M. Ahumada was supported by the Universidad del Mar and the Secretaría de Educación Pública (SEP) of Mexico through the PROMEP program. This work was performed in a Silicon Graphic Origin 300 from the Computation Center of the Universitat Politècnica de Catalunya.

Edited by: N. Pinardi

\section{References}

Alvarez, A., Tintoré, J., Holloway, G., Eby, M., and Beckers, J. M.: Effect of topographic stress on circulation in the western Mediterranean, J. Geophys. Res., 99, 16 053-16 064, 1994.

Allain, C.: Topographie dynamique et courants généraux dans le bassin occidental de la Méditerranée, Rev. Trav. Inst. Peches Marit., 24(1), 121-145, 1960.

Astraldi, M. and Gasparini, G. P.: The Seasonal Characteristics of the Circulation in the North Mediterranean Basin and Their Relationship with the Atmospheric-Climate Conditions, J. Geophys. Res., 97, 9531-9540, 1992.

Beckers J. M.: Application of the GHER 3D general circulation model to the western Mediterranean, J. Mar. Syst., 1, 315-322, 1991.

Beckers, J. M., Rixen, M., Brasseur, P., Brankart, J. M., Elmoussaoui, A., Crépon, M., Herbaut, Ch., Martel, F., Van den Berghe, F., Mortier, L., Lascaratos, A., Drakopoulos, P., Korres, G., Nittis, K., Pinardi, N., Masetti, E., Castellari, S., Carini, P., Tintoré, J., Alvarez, A., Monserrat, S., Parrilla, D., Vautard, R., and Speich, S.: Model intercomparison in the Mediterranean: MEDMEX simulations of the seasonal cycle, J. Mar. Syst., 33-34, 215-251, 2002.

Bergamasco, A., Malanotte-Rizzoli, P., Thacker, W. C., and Long, R.B.: The seasonal steady circulation of the Eastern Mediterranean determined with the adjoint method, Deep-Sea Res., 40(6), 1269-1298, 1993.

Blumberg, A. and Mellor, G.: A Description of a ThreeDimensional Coastal Ocean Circulation Model, in: ThreeDimensional Coastal Ocean Models, Coastal Estuarine Science, edited by: Heaps, N. S., American Geophysical Union, 1-16, 1987.

Brankart, J. M. and Brasseur, P.: The general circulation in the Mediterranean Sea: a climatological approach, J. Mar. Syst., 18, 41-70, 1998.

Brenner, S.: High-resolution nested model simulations of the climatological circulation in the southeastern Mediterranean Sea, Ann. Geophys., 20, 267-280, 2002.

Castellari, S., Pinardi, N., and Leaman, K.: A model study of air-sea interactions in the Mediterranean Sea, J. Mar. Syst., 18, 89-114, 1998.

Demirov, E. and Pinardi, N.: Simulation of the Mediterranean Sea circulation from 1979 to 1993: Part I. The interannual variability, J. Mar. Syst., 33, 23-50, 2002.

Drakopoulos, P. G. and Lascaratos, A.: Modelling the Mediterranean Sea: climatological forcing, J. Mar. Syst., 20, 157-173, 1999.
Echevin V., Crèpon, M., and Mortier, L.: Simulation and analysis of the mesoscale circulation in the northwestern Mediterranean Sea, Ann. Geophys., 21, 281-297, 2002.

EUROMODEL Group: Progress from 1989 to 1992 in understanding the general circulation of the Western Mediterranean Sea, Oceanologica Acta, 18, 255-271, 1995.

Fernández, V., Dietrich, D. E., Haney, R. L., and Tintoré, J.: Mesoscale, seasonal and interannual variability in the Mediterranean Sea using a numerical ocean model, Progress in Oceanography, 1-20, 2005.

Furnestin, J.: Hydrologie de la Méditerranée occidentale (Golfe du Lion, Mer Catalane, Mer d'Alboran, Corse orientale), 14 Juin-20 Juillet 1957, Rev. Trav. Inst. Peches Marit., 24(1), 5-104. 1960.

Gasparini, G. P., Zodiatis, G., Astraldi, M., Galli C., and Sparnocchia, S.: Winter intermediate water lenses in the Ligurian Sea, J. Mar. Syst., 20, 319-332, 1999.

Haines, K. and Wu, P.: A modelling study of the thermohaline circulation of the Mediterranean Sea: water formation and dispersal, Oceanologica Acta, 18(4), 401-417, 1995

Heburn, G. W.: The dynamics of the western Mediterranean Sea: A wind forced case study, Ann. Geophys., 5B, 61-74, 1987.

Herbaut, C., Mortier, L., and Crépon, M.: A sensitivity study of the General Circulation of the Western Mediterranean Sea. Part I: The Response to Density Forcing through the Straits, J. Phys. Oceanogr., 26, 65-84, 1996.

Herbaut, C., Martel, F., and Crépon, M.: A sensitivity study of the General Circulation of the Western Mediterranean Sea. Part II: The Response to Atmospheric Forcing, J. Phys. Oceanogr., 26, 65-84, 1997.

Jordà, S. G.: Towards Data Assimilation in the Catalan Continental Shelf: From data analysis to optimization methods. Ph.D. Thesis. Universitat Politècnica de Catalunya, 333 p., 2005.

Korres, G. and Lascaratos, A.: A one-way nested eddy resolving model of the Aegean and Levantine basins: implementation and climatological runs, Ann. Geophys., 21, 205-220, 2003.

Lascaratos, A. and Nittis, K.: A high-resolution three-dimensional numerical study of intermediate water formation in the Levantine Sea, J. Geophys. Res., 103, 18 497-18 511, 1998.

La Violette, P. E.: The Western Mediterranean Circulation Experiment (WMCE): Introduction, J. Geophys. Res., 95(C2), 15111514, 1990.

Malanotte-Rizzoli, P. and Bergamasco, A.: The general circulation of the eastern Mediterranean. Part I: The barotropic wind driven circulation, Oceanologica Acta, 12, 335-351, 1989.

Malanotte-Rizzoli, P. and Bergamasco, A.: The wind and thermally driven circulation of the eastern Mediterranean Sea. Part II: The baroclinic case, Dyn. Atmos. Oceans, 15, 355-419, 1991.

Madec, G., Chartier, M., and Crépon, M.: The effect of the thermohaline forcing variability on deep-water formation in the western Mediterranean Sea: a high-resolution three-dimensional numerical study, Dyn. Atmos. Oceans, 15(3-5), 301-332, 1991a.

Madec, G., Delecluse, P., and M. Crépon, M.: Numerical study of deep-water formation in the western Mediterranean Sea, J. Phys. Oceanogr., 26, 1349-1371, 1991b.

Menzin, A. B. and Moskalenko, L. V.: Calculation of wind driven currents in the Mediterranean Sea by the electrical simulation method, Oceanologica, 22, 537-540, 1982.

Mellor, G.: An equation of state for numerical models of oceans and estuaries, J. Atmos. Oceanic Tech., 8, 609-611, 1991. 
Mellor, G.: User's Guide for a Three-Dimensional Primitive Equation, Numerical Ocean Model. Princeton University, Princeton, N.J., 1-56, 2004

Mellor, G. and Blumberg, A. F.: Modeling Vertical and Horizontal Diffusivities with the Sigma Coordinate System, Mon. Weather Rev., 113, 1279-1383, 1986.

Mellor, G. and Yamada, T.: Development of a turbulence closure sub-model for geophysical fluid problems, Rev. Geophys., 20, 851-875, 1982

Millot, C.: Circulation in the Western Mediterranean Sea, Oceanologica Acta, 10, 143-149, 1987.

Millot, C.: Mesoscale and seasonal variability of the circulation in the western Mediterranean, Dyn. Atmos. Oceans, 15, 179-214, 1991.

Millot, C.: Circulation in the Western Mediterranean Sea, J. Mar. Syst., 20, 423-442, 1999.

Molcard, A., Pinardi, N., Iskandarani, M., and Haidvogel, D. B.: Wind driven general circulation of the Mediterranean Sea simulated with a Spectral Element Ocean Model, Dyn. Atmos. Oceans, 35, 97-130, 2002.

Nielsen, J. N.: Hydrography of the Mediterranean and Adjacent Waters, Report on the Danish Oceanography Expeditions, 77192, 1912.

Ovchinnikov, I. M.: Circulation in the surface and intermediate layers of the Mediterranean Sea, Oceanology, 6, 48-59, 1966.

Pinardi, N. and Navarra, A.: Baroclinic wind adjustment processes in the Mediterranean Sea, Deep-Sea Res., 40, 1299-1326, 1993.

Pinardi, N. and Masetti, E.: Variability of the large-scale general circulation of the Mediterranean Sea from observations and modelling: a review, Palaeogeography, Palaeoclimatology, Palaeoecology, 158, 153-173, 2000.

Pinardi, N., Allen, I., Demirov, E., De Mey, P., Korres, G., Lascaratos, A., Le Traon, P.Y., Maillard, C., Manzella, G., and Tziavos, C.: The Mediterranean ocean forecasting system: first phase of implementation (1998-2001), Ann. Geophys., 21, 3-20, 2003.

Roussenov, V., Stanev, E., Artale, V., and Pinardi, N.: A seasonal model of the Mediterranean Sea general circulation, J. Geophys. Res., 100, 13 515-13 538, 1995.

Send, U., Font, J., Krahmann, G., Millot, C., Rhein, M., and Tintoré, J.: Recent advances in observing the physical oceanography of the western Mediterranean Sea, Progress Oceanogr., 44, 3764, 1999.
Smagorinsky, J.: General Circulation Experiments with the Primitive Equations, Mon. Weather Rev., 91(3), 99-165, 1963.

Sorgente, R., Drago, A. F., and Ribotti, A.: Seasonal variability in the Central Mediterranean Sea circulation, Ann. Geophys., 21, 299-322, 2003.

Stanev, E. V., Friedrich, H. J., and Botev, S.: On the seasonal response of intermediate and deep water to surface forcing in the Mediterranean Sea, Oceanologica Acta, 12, 141-149, 1989.

Tonani, M.: Studi della predicibilità della circolazione del Mar Mediterraneo. Ph.D. Thesis. Università degli Studis di Bologna, 139 p., 2003.

Tziperman, E. and Malanotte-Rizzoli, P.: The climatological seasonal circulation of the Mediterranean Sea, J. Mar. Res., 49, 411434, 1991.

WMCE Group: Seasonal and Interannual Variability of the Western Mediterranean Sea, Coastal and Estuarine Studies, edited by: La Violette, P. E., American Geophysical Union, 6, 373, 1994.

Wu, P. and Haines, K.: Modelling the dispersal of Levantine Intermediate Water and its role in Mediterranean deep-water formation, J. Geophys. Res., 101(C3), 6591-6607, 1996.

Wüst, G.: On the vertical circulation of the Mediterranean Sea, J. Geophys. Res., 66, 3261-3271, 1961.

Younes, W. A. N., Bensoussan, N., Romano, J. C., Arlhac, D., and Lafont, M. G.: Seasonal and Interannual variations (1996-2000) of the coastal waters east of the Rhone River mouth as indicated by the SORCOM series, Oceanologica Acta, 26, 311-321, 2003.

Zavatarelli, M. and Mellor, G.: A numerical study of the Mediterranean Sea Circulation, J. Phys. Oceanogr., 25, 1384-1414, 1995.

Zavatarelli, M., Baretta, J. W., Baretta-Bekker, J. G., and Pinardi, N.: The dynamics of the Adriatic Sea ecosystem: An idealized model study, Deep-Sea Res., 47, 937-970, 2000.

Zavatarelli, M., Pinardi, N., Kourafalou, V. H., and Maggiore, A.: Diagnostic and prognostic model studies of the Adriatic Sea general circulation: Seasonal variability, J. Geophys. Res., 107, 1$20,2002$.

Zavatarelli, M. and Pinardi, N.: The Adriatic Sea modelling system: a nested approach, Ann. Geophys., 21, 345-364, 2003. 